\title{
SOCIEDADE CIVIL, CONSELHOS GESTORES DE POLÍTICAS PÚBLICAS E SUAS ESTRATÉGIAS DE DESENVOLVIMENTO SOCIAL MUNICIPAL
}

\author{
CIVIL SOCIETY, PUBLIC POLICY ADVICE MANAGERS AND \\ DEVELOPMENT STRATEGIES IN SOCIAL HALL
}

\author{
Silmara Carneiro e Silva ${ }^{1}$ \\ Danuta Estrufika Cantóia Luiz ${ }^{2}$
}

\begin{abstract}
RESUMO
O presente artigo reflete sobre a relevância da participação da sociedade civil nos conselhos gestores de políticas públicas frente ao processo de desenvolvimento social na esfera municipal. Foi construído por meio de pesquisa qualitativa, com referencial teórico pautado em autores que discutem as temáticas: democracia, sociedade civil, poder local institucionalizado, políticas públicas (sociais) e desenvolvimento social municipal. Visa contribuir com o debate acadêmico em torno das temáticas abordadas e principalmente sobre a relevância dos conselhos gestores de políticas públicas como espaços de protagonismo para o fomento do debate do desenvolvimento social. Inscreve-se como uma contribuição para a análise de perspectivas contra-hegemônicas, engendradas na sociedade civil, em sua relação com os avanços necessários no âmbito das instituições democráticas na contemporaneidade. Inscreve-se, ainda, como uma contribuição para o debate dos avanços da inserção da sociedade civil nas políticas públicas (sociais) nos poderes locais como condição necessária para o processo de desenvolvimento social municipal.
\end{abstract}

Palavras-chave: Democracia. Sociedade civil. Poder local institucionalizado. Conselhos gestores de políticas públicas. Desenvolvimento social municipal.

\begin{abstract}
This article reflects on the relevance of civil society participation in public policy management councils regarding the process of social development at the municipal level. It was built through qualitative research, theoretical ruled by authors who discuss topics: democracy, civil society, local institutionalized public policies (social) and local social development. It aims to contribute to the academic debate and professional social work around the issues addressed and mostly on the relevance of public policy management councils as areas of leadership in fostering social development debate. Sign up as a contribution to the analysis of counterhegemonic perspectives engendered in civil society in its relationship with the advances needed in the context of democratic institutions in contemporary society. Sign up, yet, as a contribution to the discussion of advances in integration of civil society in public policy (social) in the local government as a necessary condition for the process of municipal social development.
\end{abstract}

\footnotetext{
${ }^{1}$ Doutoranda em Serviço Social e Política Social pela Universidade Estadual de Londrina. Assistente Social da Secretaria de Estado da Família e Desenvolvimento Social do Paraná. E-mail: verdesilmara@yahoo.com.br.

${ }^{2}$ Doutora em Serviço Social pela Pontifícia Universidade Católica de São Paulo. Professora do Departamento de Serviço Social e do Mestrado em Ciências Sociais Aplicadas da UEPG. E-mail: danutaluiz88@gmail.com.
} 
Keywords: Democracy. Civil society. Local institutionalized. Councils policymakers. Municipal social development.

\section{Introdução}

O presente artigo se inscreve no debate sobre um dos desafios da democracia contemporânea: a participação da sociedade civil nos espaços democráticos participativos institucionalizados, em especial, nos conselhos gestores de políticas públicas, considerando-os como espaços legítimos de participação da sociedade civil, nos quais as políticas públicas são planejadas, avaliadas, fiscalizadas e aprimoradas nas diferentes esferas de governo, seja federal, estadual ou municipal.

No Brasil, os municípios são entes federados autônomos, responsáveis pela gestão das políticas públicas, uma vez que estas são geridas a partir do sistema descentralizado e participativo. É nesse âmbito dos municípios brasileiros que o processo de estruturação dos conselhos gestores de políticas públicas é protagonizado. Nestes, os diferentes segmentos organizados da sociedade civil local inscrevem-se como sujeitos participantes e ativos do processo de gestão das políticas públicas e no fomento ao debate sobre o desenvolvimento social no país. São espaços por meio dos quais a sociedade civil pode pautar a agenda pública local e, dessa forma, contribuir com avanços necessários para gestão das políticas públicas nas esferas municipais voltadas a esse desenvolvimento.

A partir desse marco, objetiva-se, neste artigo, refletir sobre a relevância da participação da sociedade civil no âmbito dos conselhos gestores de políticas públicas. Delimita-se a identificar tal relevância no que tange ao fomento do debate do desenvolvimento social nas esferas municipais. Entende-se que o grau de envolvimento dos conselhos gestores, nesse debate, possa otimizar a inscrição, na agenda das políticas públicas, de ações que se voltem a esse desenvolvimento. Como expressão de uma aproximação a esse campo temático, o artigo foi elaborado, a partir de pesquisa qualitativa construída com o uso de revisão bibliográfica, para a qual foram consideradas relevantes as contribuições de autores que, na área das ciências sociais aplicadas, destacam-se entre os que se filiam à vertente teórica marxista em sua pers- pectiva gramsciana. É por meio dessas contribuições que aproxima-se, nesse artigo, de temáticas como democracia, sociedade civil, poder local institucionalizado e políticas públicas (sociais). São temáticas necessárias para o debate do desenvolvimento social, no âmbito municipal.

\section{As relações entre sociedade civil, estado e democracia na contemporaneidade}

A democracia é um sistema de governo que possui diferentes contornos ao longo da história. Sánchez Vázquez (2001, p. 90) alerta que ela “[...] não pode se abstrair da realidade e sua história. Suas formas, suas possibilidades, sua extensão e seus limites se acham condicionados historicamente. A democracia não é uma planta que floresce em qualquer terreno histórico e social".

É a partir das práticas sociais, dos valores, da cultura, dos interesses e das racionalidades estabelecidos pelos diversos sujeitos políticos ${ }^{3}$ presentes na sociedade civil, construídos sob a determinação de diferentes contextos históricos, que as diferentes perspectivas ideopolíticas da democracia são produzidas nas sociedades.

$\mathrm{Na}$ sociedade moderna, várias foram as perspectivas de democracia construídas com as lutas entre a hegemonia e a contra-hegemonia. $\mathrm{O}$ antagonismo entre as classes sociais foi e ainda é a questão central que determina o campo de tensões que é materializado no âmbito das relações entre Estado e sociedade civil no âmbito das instituições democráticas.

Dentre outras abordagens sobre a democracia ${ }^{4}$, a gramsciana se propõe a discutir mais amplamente

\footnotetext{
${ }^{3}$ Silva e Silva (2009) tratando dos diferentes sujeitos políticos presentes na sociedade faz referência aos seguintes: grupos de pressão, movimentos sociais e outras organizações da sociedade; partidos políticos, administradores e burocratas, técnicos, planejadores e avaliadores, judiciário e a mídia.

4 No debate contemporâneo, as teorias democráticas são frutos de abordagens diferenciadas, as quais podemos sintetizar nas seguintes: as neoliberais; a habermaseana e a marxista gramsciana, conforme Robert Dahl e Antony Downs (neoliberais); democracia deliberativa (interpretação habermaseana) para a qual a democracia deliberativa é uma alternativa às democracias liberal e republicana e a abordagem marxista gramsciana que será apresentada no decorrer do presente texto.
} 
a política, a cultura, a sociedade civil e as classes subalternas a partir de seus elementos contra-hegemônicos, enquanto campos profícuos para as lutas pela hegemonia no âmbito do regime democrático, frente às determinações burguesas.

O Estado, para a perspectiva gramsciana, se configura como um Estado Ampliado ${ }^{5}$, resultado da compreensão de "[...] elementos políticos e sociais; da força das instituições e da liberdade dos organismos privados; da inter-relação entre estrutura e superestrutura; da compenetração do aparelho estatal com a sociedade civil organizada" (SEMERARO, 1999, p. 75). A partir dessa lógica, a sociedade civil, para Gramsci, se constitui pelo conjunto de organizações responsáveis por formar e difundir ideologias na sociedade.

$\mathrm{Na}$ interpretação gramsciana, as organizações da sociedade civil são denominadas de mecanismos privados de hegemonia e, podem ter acesso ao Estado de forma a inscrever, no espaço democrático, diferentes perspectivas contra-hegemônicas à lógica democrática dominante. Dessa forma, a sociedade civil se inscreve no seio do movimento histórico, econômico, político e cultural como uma “[...] esfera em que as classes organizam e defendem seus interesses e disputam a hegemonia" (DURIGUETTO, 2007, p. 55). Configura-se como:

[...] palco de um pluralismo de organismos coletivos ditos "privados" (associações e organizações, sindicatos, partidos, atividades culturais, meios de comunicação etc.), é a nova configuração da dinâmica social, na qual se precisava repensar a política e sua relação com as esferas da vida social e elaborar os novos termos da hegemonia. (DURIGUETTO, 2007, p. 55).

Segundo Coutinho (2000, p. 170), Gramsci havia percebido, na sociedade civil, uma nova esfera do ser social:

[...] o mundo das auto-organizações, do que ele chamou de "aparelhos privados de hegemonia". São os partidos de massa, os sindicatos, as diferentes associações, os movimentos sociais etc., tudo aquilo que resulta de uma crescente "socialização da política", ou seja, do ingresso na esfera pública

\footnotetext{
${ }^{5}$ Gramsci defende a noção de Estado Ampliado, gestada em sua produção teórica, que se consolidou durante seu encarceramento na primeira metade do século XX em decorrência de sua resistência ao regime fascista na Itália de Mussolini.
}

de um número cada vez maior de novos sujeitos políticos individuais e coletivos.

A partir dos elementos constitutivos da sociedade civil na interpretação gramsciana, Simionatto (1999) a sintetiza como o momento da superestrutura ideológico-política. Na sua interação com a sociedade política, a sociedade civil conforma o conceito de Estado Ampliado de Gramsci. A sociedade política, por sua vez, é configurada como o "[...] conjunto de aparelhos através dos quais a classe dominante impõe coercitivamente a sua dominação (aparato policial e militar, sistema judiciário e administrativo)" (DURIGUETTO, 2007, p. 56).

Verifica-se, portanto, que, inserida no âmbito da tradição marxista, a interpretação gramsciana impõe para o debate democrático e para o exame do Estado novos elementos provenientes da configuração da sociedade civil. Somados aos demais elementos próprios da interpretação elaborada pelo materialismo histórico de Karl Marx, a visão gramsciana faz frente aos ideais democráticos liberais para os quais a democracia é apenas um meio para a garantia da hegemonia burguesa e da manutenção da sociedade nos moldes capitalistas. Assim, é uma leitura que contribui significativamente para pensar a relação entre sociedade civil e Estado, à luz da transformação de suas estruturas tradicionais e da incorporação de novos elementos provenientes das perspectivas ideopolíticas e de desenvolvimento contra-hegemônicas à ordem burguesa.

A compreensão gramsciana vislumbra a magnitude da participação da sociedade civil enquanto uma possibilidade histórica capaz de alterar a estrutura estatal, imprimindo à mesma outra dimensão, a do consenso. Seu objetivo é uma abertura democrática maior, na qual as classes subalternas passam a poder participar da disputa pela hegemonia. Nesse sentido, o Estado deixa de significar somente uma instituição coercitiva, para ser também uma esfera consensual, na qual a dinâmica da sociedade civil passa a interagir junto à sociedade política. E uma vez que não há mais possibilidade de sustentação hegemônica somente a partir da coerção, as classes dominantes passam a aceitar a nova gramática histórica democrática, possibilitada, sobremaneira, pela pressão popular, na qual o consenso se torna um valor relevante no âmbito estrutura política moderna. 
A democracia, para Coutinho (2006, p. 13), é "[...] reivindicada por praticamente todas as correntes ideológicas, da direita à esquerda". No entanto, embora a democracia, a conquista e o usufruto das liberdades e dos direitos políticos sejam conquistas universais na sociedade moderna, faz-se necessário a discussão acerca das diferentes perspectivas ideopolíticas, socioculturais e de desenvolvimento que permeiam a batalha das ideias democráticas. A democracia não é um sistema de governo estático, mas se configura como um processo histórico e social que possui a capacidade de agregar valores distintos, dependendo das forças hegemônicas em jogo na política.

Para uma perspectiva radical de democracia, sua natureza e configuração estão voltadas ao "[...] sentido da igualdade material, da participação coletiva de todos na apropriação dos bens coletivamente criados etc." (COUTINHO, 2006, p. 26), divergente em essência da noção de democracia liberal enquanto "regras do jogo" político para manter os interesses das elites dominantes. A democracia, enquanto processo, se constrói em meio às lutas entre a hegemonia e a contra-hegemonia, na qual, de um lado, as classes subalternas buscam a garantia de direitos e a ampliação do cânone democrático, e as classes burguesas reclamam lugar privilegiado no âmbito das camadas cultural, econômica e política, a fim de comandar os rumos do desenvolvimento na sociedade - a hegemonia. Nesse sentido, Estado e sociedade civil se relacionam em meio ao campo de disputas pela hegemonia, por meio de lutas nas quais se discute a manutenção, a mudança e a transformação societária.

$\mathrm{Na}$ perspectiva gramsciana, hegemonia diz respeito "[...] à direção da sociedade num determinado contexto ou período histórico" (GRUPPI, 1978, p. 1). Duriguetto (2007, p. 59) aponta que

A noção de hegemonia como "direção intelectual e moral" assume relevância central na estratégia da "guerra de posição". O conceito se refere tanto ao processo em que uma classe torna-se dirigente quanto à direção que uma classe no poder exerce sobre o conjunto da sociedade.

Assim, as classes subalternas que, ao longo do desenvolvimento da democracia liberal burguesa, sofreram as consequências dos privilégios concedidos às classes dominantes, viram nascer, no âmbito dos processos de guerra de posições, a possibilidade de socialização da política e da ampliação do Estado. Tais possibilidades são anunciadas por Gramsci como possibilidades históricas de enfrentamento à ditadura burguesa, geradora de desigualdades na distribuição da riqueza socialmente construída e do poder no âmbito do Estado.

Com efeito, Gramsci tornou-se uma referência para o pensamento democrático radical na sociedade moderna. Na contemporaneidade, seus escritos contribuem para a formação de um pensamento de democracia contra-hegemônico à democracia burguesa. Uma democracia resultante da dialética histórica e social na qual estão implicadas não somente as classes dominantes, mas todo o tecido social, as classes subalternas e suas demandas societais, as quais passam a ser legítimas no âmbito da política.

A participação direta da sociedade civil nos espaços institucionalizados da democracia pode evidenciar a abertura de campo de possibilidades no sentido da ampliação do debate democrático na sociedade. Experiências dessa natureza importam ao desenvolvimento da democracia na contemporaneidade, fortalecem suas instituições e distribuem o poder, socializando a política, permitindo que novos patamares de desenvolvimento possam ser alcançados na medida em que novas perspectivas ideopolíticas, socioculturais e de desenvolvimento sejam incorporadas hegemonicamente pela esfera estatal, pela política e pela sociedade em seu conjunto.

A partir dessa lógica de entendimento gramsciano de participação da sociedade civil no âmbito do Estado, a democracia participativa pode ser discutida a partir da abertura do Estado para a absorção dos diferentes sujeitos políticos oriundos da sociedade, os quais - enquanto sujeitos coletivos inerentes à sociedade civil - disputam a hegemonia no âmbito das instituições democráticas e lutam pela direção da ordem societária. À luz de perspectivas contra-hegemônicas, os sujeitos coletivos podem travar uma guerra de posições no âmbito do Estado e, de tal forma, contrapor-se à ordem democrática burguesa.

Complementando essa posição - de que é no plano da sociedade e das relações entre seus sujeitos políticos que o Estado é chamado a ampliar-se -, que se considera o conceito de participação como "protagonismo" do sujeito em relação a sua história como um dos elementos para que se alcance a dimensão 
coletiva da ação (GOHN, 2005a). Um protagonismo que encontra na sociedade civil os ingredientes históricos, sociais e culturais necessários ao fortalecimento das instituições democráticas, bem como para o avanço do patamar de desenvolvimento societário.

No âmbito das discussões entre as relações entre a sociedade civil, a democracia e a participação, Teixeira (2001, p. 30) aponta que a “[...] participação cidadã utiliza-se não apenas de mecanismos institucionais já disponíveis ou a serem criados, mas os articula a outros mecanismos e canais que se legitimam pelo processo social". Nesse sentido, a participação cidadã é uma alternativa ao fortalecimento democrático, a partir da construção de uma nova cultura política emergente que nasce da resistência aos pactos de centralização de poder e de autoritarismo, reinventando a política para além dos mecanismos tradicionais de participação democrática.

Cabe, finalmente, acrescentar, ainda no tange dos desdobramentos da participação da sociedade civil no Estado, a relação entre democracia e liberdade. Para Sánchez Vázquez (2001, p. 69) a “[...] verdadeira democracia aparece assim vinculada necessariamente à liberdade". E liberdade, nesse sentido, é interpretada como possibilidade, conforme Gramsci (2001, p. 406):

Possibilidade quer dizer "liberdade". A medida das liberdades entra no conceito de homem. Que existam as possibilidades objetivas de não se morrer de fome e que, mesmo assim, se morra de fome, é algo que, ao que parece, tem sua importância. Mas a existência das condições objetivas - ou possibilidade, ou liberdade - ainda não é suficiente: é necessário "conhecê-las" e saber utilizá-las. Querer utilizá-las.

De acordo com Semeraro (1999, p. 161) a concepção de liberdade gramsciana "[...] tem a conotação positiva de expansão social, não de cerceamento e limitação: a liberdade individual não termina onde começa a dos outros, mas se desenvolve ainda mais quando se encontra com a dos outros" (SEMERARO, 1999, p. 161).

Portanto, a democracia, na visão gramsciana, não se constitui a partir de uma liberdade formal, mas de uma liberdade capaz de garantir a igualdade material, pela qual as classes subalternas possam acessar substancialmente os bens socialmente construídos, bem como o poder político democrático, uma vez que as "[...] múltiplas objetivações que formam a democracia moderna surgem como respostas, dadas em determinado nível concreto do processo de socialização do trabalho, ao desenvolvimento correspondente dos carecimentos de socialização da participação política" (COUTINHO, 2000, p. 23).

De tal modo, pensar na relação entre sociedade civil, Estado e democracia à luz de perspectivas contra-hegemônicas à ordem burguesa implica não excluir do debate as possibilidades de luta existentes, ainda que nos limites da ordem burguesa, pois já na interpretação marxista se alertara com relação à necessidade de desenvolver as forças produtivas no âmbito da sociedade capitalista como forma de superação da referida ordem. Outrossim, a luta não se restringe à estrutura econômica, mas é essencialmente política. Assim, a partir dos limites da ordem democrática, vislumbrar sua ampliação é um caminho possível para o desenvolvimento econômico, político e cultural da sociedade rumo à superação dos limites da democracia burguesa.

\section{Desafios para a formação de uma nova cultura política democrática no Brasil: reflexões sobre os conselhos municipais gestores de políticas públicas}

O fortalecimento das instituições democráticas é uma possibilidade histórica na medida em que haja maior abertura para a socialização da política nos espaços de poder político. Ele está vinculado, dentre outros fatores, à cultura política inerente aos processos de disputa pela hegemonia, pois no âmbito das relações sociais, elementos ideológicos subsidiam as disputas de poder e luta pela hegemonia, fazendo vivificar a cultura - ou "as culturas" -presente em uma determinada realidade social ou período histórico.

As culturas e as ideologias estão imbricadas em uma mesma trama de relações, constituindo-se interdependentes no campo da política. Alvarez, Dagnino e Escobar (2000, p. 25) apontam que a “[...] cultura é política porque os significados são constitutivos dos processos que, implícita ou explicitamente, buscam redefinir o poder social".

A cultura política se reproduz em uma dimensão simbólica e por vezes institucionaliza as representações acerca da natureza das relações econômicas, sociais e culturais da sociedade civil. 
Assim, é determinada pelos mesmos conflitos, contradições e interesses existentes no âmbito da sociedade civil. Desse modo, tais elementos interferem na dinâmica das expressões da democracia, na medida em que determinam a lógica das relações de disputa pela hegemonia no âmbito das instituições democráticas. "A batalha cultural apresenta-se, por conseguinte, como elemento central na construção da hegemonia, na conquista do consenso e da direção político-ideológica por parte das classes subalternas" (SIMIONATTO, 2009, p. 46).

No Brasil, o particularismo, o corporativismo e o clientelismo são marcas históricas que caracterizaram a cultura política, determinam a formação do poder e as perspectivas democráticas dominantes. $\mathrm{O}$ caráter hegemônico do Estado brasileiro pautado no patriarcalismo, na meritocracia e na cultura da liberal burguesa, construiu historicamente uma democracia intimamente compromissada com a manutenção dos interesses das classes dominantes no país, cujas perspectivas ideopolíticas, culturais e de desenvolvimento estiveram, historicamente, voltadas à garantia dos meios de produção e dos interesses dos senhores rurais e da burguesia agroindustrial brasileira.

Com a proclamação da República em 1889, o Brasil demarcou historicamente a democracia como sistema de governo, mas foi com a revolução de 1930 que se solidificou no país uma democracia hegemonicamente de caráter liberal. Atrelado à burguesia agrária industrial, o governo de Vargas manteve um padrão de desenvolvimento conservador, que se firmou nacionalmente à custa da conservação de uma estrutura socioeconômica desigual. Embora com avanços do ponto de vista dos direitos trabalhistas, o regime democrático brasileiro se consolidou enquanto uma democracia formal, para a qual a igualdade material não foi incorporada no conceito de liberdade defendido pelo Estado e para o qual as demandas das classes subalternas foram sendo tratadas como "caso de polícia". Imperando, portanto, no tratamento das refrações da questão social a atuação dos aparelhos repressores inerentes à sociedade política brasileira.

No Brasil, o padrão de intervenção estatal na consolidação da modernização capitalista conformou uma dinâmica social em que as ações e demandas das classes subalternas foram incorporadas sob a lógica da repressão, do clientelismo, do paternalis- mo e do autoritarismo (DURIGUETTO, SOUZA E SILVA, 2009, p. 14).

A contra-hegemonia, engendrada no âmbito dos segmentos organizados da sociedade civil brasileira, sofreu à duras penas, sob as consequências de uma sociedade desigual, na qual a maioria da população formou-se historicamente em condição de subalternidade. Na condição de ex-escravo ou na condição de imigrante europeu trazido pelo governo brasileiro no início do século XX, a população estrangeira constituiu a mão de obra disponível para servir ao desenvolvimento da economia no país:

O caráter antidemocrático da nossa modernização capitalista teve no aparelho estatal um papel decisivo para a sua implementação, revelado pela exclusão da participação popular nos processo de decisão das questões políticas que ordenaram as relações entre Estado, classes dominantes e as classes subalternas (DURIGUETTO, SOUZA E SILVA, 2009, p. 14).

A abertura e a reforma democrática no Brasil foram árduas conquistas de sujeitos políticos advindos da sociedade civil, que lutaram contra o regime ditatorial instalado. A década de 1980 no país foi palco de uma "crise orgânica", que aos moldes do conceito gramsciano, "[...] é uma crise geral (econômica, política, moral) que pode se apresentar inicialmente como crise de direção, mas tem raízes profundas na formação econômica social" (SCHLESENER, 2007, p. 22). Seu resultado constituiu-se de uma série de concessões por parte das classes dominantes frente a um contexto de luta e de conquista por parte das classes subalternas. (MOTA, 2005).

A promulgação da Constituição Federal de 1988 foi o desfecho da denominada crise orgânica vivida pela sociedade brasileira, que resultou das contradições desse "bloco histórico" no Brasil. Denominada de Constituição Cidadã, foi garantidora de uma série de benefícios à sociedade civil. A federalização ${ }^{6}$ e a incorporação dos institutos democráticos participativos foram uma das principais conquistas para a democracia brasileira nesse contexto. Outra conquista foi a garantia constitucional do tripé da seguridade social, com as políticas de previdência,

\footnotetext{
${ }_{6}$ "Em suma, como em qualquer federalização, no Brasil pós 1988, a autoridade política de cada nível de governo é soberana e independente das demais" (ARRETCHE, 2000, p. 47).
} 
saúde e assistência social, políticas estas que compuseram o padrão de proteção social do país. Essas são questões que contribuíram, a partir de então, significativamente para a ampliação do cânone democrático e para mudanças no padrão de desenvolvimento no país, respectivamente, fazendo frente à contrarreforma neoliberal imposta ao Brasil na década de 1990.

Com a federalização, o Brasil passou a adotar o sistema descentralizado ${ }^{7}$ e participativo de gestão das políticas públicas e as instâncias federadas conquistaram autonomia política e administrativa na condução das mesmas a partir de 1988. No entanto, para a materialização dos preceitos constitucionais, é necessário que tais espaços de participação da sociedade civil no âmbito do Estado ocupem seus lugares de modo a contribuir para a construção de uma cultura política propícia ao fortalecimento do debate público, para a expansão do conceito de liberdade e de direitos, para a incorporação de novos valores e perspectivas no campo das instituições democráticas, a partir de concepções construídas a partir da reforma intelectual e moral engendrada no seio das classes subalternas que, acessando ao Estado, passam a constituir o conteúdo democrático universal.

O debate da democracia participativa no Brasil remonta à década de 1980 , do século passado, para tratar de um contexto privilegiado em que essa modalidade de democracia, não hegemônica, alcança status jurídico-formal no país. Com a Constituição Federal de $1988^{8}$, conquista-se uma "nova institucionalidade pública" (GOHN, 2005) no âmbito da democracia brasileira. Nesta, a institucionalidade pública passou a portar

[...] duas importantes mudanças no processo de elaboração de políticas governamentais, a saber: a descentralização, isto é, a transferência da responsabilidade decisória para as unidades subnacionais (estados e municípios), e o viés claramente participativo que, a partir daquele momento, deveria caracterizar o processo decisório [...] (PERISSINOTTO, 2004, p. 48).

\footnotetext{
${ }^{7}$ Entenda-se por descentralização a "institucionalização no plano local de condições técnicas para a implementação de tarefas de gestão de políticas sociais" (ARRETCHE, 2000, p. 16).

${ }^{8}$ Em 1981, era prevista a participação da sociedade civil na gestão da política de meio ambiente, por meio do conselho nacional do meio ambiente e, ainda em 1984, a lei de execução penal previa o Conselho da Comunidade (BIDARRA, 2004).
}

A partir da década de 1990, portanto, os conselhos gestores de políticas públicas se multiplicaram pelo país, incorporando a participação da sociedade civil na esfera da gestão das políticas, como saúde, educação, assistência social, trabalho, entre outras. A sociedade civil constituiu-se parte integrante desses espaços, contribuindo com o processo político a partir de suas perspectivas ideológicas, políticas e culturais, na busca de formatar consensos normativos frente às questões pertinentes a cada uma das respectivas políticas. Conforme Tatagiba (2002) "Os conselhos gestores de políticas públicas são, portanto, espaços públicos de composição plural e paritária entre Estado e sociedade civil, de natureza deliberativa, cuja função é formular e controlar a execução das políticas públicas setoriais" (itálicos no original).

No Brasil, a articulação do Estado com a sociedade civil, suas relações, a partilha de interesses e proposições encontraram seu lugar no âmbito dos espaços democráticos participativos dos poderes locais institucionalizados, sendo os conselhos gestores de políticas públicas espaços fundamentais no contexto democrático nacional por oferecerem condições para a materialização dos novos preceitos democráticos na esfera da estrutura estatal, advindos dos princípios e dos valores pertencentes a uma ideia de democracia contra-hegemônica à dominação burguesa. Assim, os conselhos gestores de políticas públicas foram, ao longo do final do século XX e início do século XXI, os canais mais relevantes em termos de acesso das sociedades civis locais às instituições participativas da democracia brasileira.

O fortalecimento de uma teia de relações culturais específicas favorece o desenvolvimento das ideologias na sociedade, influenciando nos processos de participação dos diferentes segmentos organizados da sociedade civil em meio aos espaços institucionalizados. Portanto, a cultura é aqui interpretada não como "[...] uma esfera, mas uma dimensão de todas as instituições - econômicas, sociais e políticas. Cultura é um conjunto de práticas materiais que constituem significados, valores e subjetividades" (JORDAN E WEEDON, 1995, p. 8 apud ALVAREZ, DAGNINO E ESCOBAR, 2000, p. 18) (itálicos no original).

Com base na noção de Estado ampliado em Gramsci, as instituições democráticas participativas 
podem ser consideradas estruturas profícuas para a relação entre sociedade civil e sociedade política. No âmbito dos poderes locais institucionalizados, as instituições democráticas participativas que propiciam maior acesso da sociedade civil às estruturas estatais são os conselhos gestores de políticas públicas, que se tornam um conjunto de instituições profícuas de análise sobre a cultura política no domínio dos poderes locais institucionalizados. É no contexto dos referidos conselhos que, nos municípios brasileiros, é possível de se verificar condições para o aprofundamento da discussão sobre os elementos presentes na cultura política dos sujeitos políticos da sociedade civil e para a incorporação de suas perspectivas ideopolíticas, socioculturais e de desenvolvimento nos itinerários políticos institucionalizados, enquanto uma experiência de fortalecimento das instituições democráticas e de avanço e consolidação das políticas públicas sociais. Assim, vislumbra-se os conselhos gestores de políticas públicas como potenciais espaços de fomento para o debate sobre o desenvolvimento social das municipalidades. Os limites e desafios do protagonismo dos conselhos gestores de políticas públicas para pautar as agendas públicas locais estão sendo vivenciados pelos poderes locais institucionalizados, de tal forma que os municípios se tornam os entes da federação que protagonizam esse processo na esfera da democracia brasileira junto da sociedade civil nos espaços locais. Condição esta que lhes atribui importância significativa em meio ao debate acadêmico sobre a sociedade civil e a democracia na contemporaneidade.

\section{As possibilidades de contra-hegemonia nos poderes locais institucionalizados: reflexões sobre o processo de formação de estratégias de desenvolvimento social municipal}

A contribuição da contra-hegemonia para as políticas públicas (sociais), frente ao processo desenvolvimento social municipal no poder local, se dá em meio a um território de lutas, no qual as relações de forças entre os diferentes sujeitos mudam e podem definir os rumos da democracia e do desenvolvimento no âmbito do poder local institucionalizado.

Segundo Fischer (1993, p. 10 - 11)
[...] invariavelmente a análise do "local" remete ao estudo do poder enquanto relações de forças, por meio das quais se processam as alianças e os confrontos entre atores sociais, bem como ao conceito de espaço delimitado e a formação de identidades e práticas políticas específicas.

Nesse processo de construção democrática, inscrito dentro do modo de produção capitalista, no qual as relações de forças entre os diferentes segmentos da sociedade civil determinam a direção da sociedade e configuram a estrutura jurídica e política do Estado, Vieira (1992, p. 98) dispõe que

A política social consiste em estratégia governamental e normalmente se exibe em forma de relações jurídicas e políticas, não podendo ser compreendida por si mesma [...] é uma maneira de expressar as relações sociais, cujas raízes se localizam no mundo da produção (VIEIRA, 1992, p. $21,22)$.

Assim, a “[...] política social expressa e carrega encargos do Estado, materializados em serviços e em atividades de natureza pública e geral, encargos estes também voltados à reprodução da força de trabalho de que o capitalismo não pode prescindir" (VIEIRA, 1992, p. 98). No contexto dos conselhos municipais gestores de políticas públicas (sociais), as classes subalternas presentes no espaço local podem acessar o Estado e, uma vez conquistados espaços de debates na arena pública de discussões, podem disputar a hegemonia. Para tanto, ressalta-se a importância da reforma intelectual e moral das classes subalternas, como condição necessária à disputa pela hegemonia por parte destas no âmbito das instituições democráticas. A luta pela garantia dos serviços disponibilizados via políticas públicas (sociais) à sociedade são demandas das classes subalternas, que buscam respostas do Estado frente aos direitos sociais já conquistados. Estes, na análise de Vieira (1992, p. 23),

[...] significam antes de mais nada a consagração jurídica de reivindicações dos trabalhadores. Não significam a consagração de todas as reivindicações populares, e sim a consagração daquilo que é aceitável para o grupo dirigente no momento.

Entretanto os interesses das classes subalternas e dos demais aparelhos privados de hegemonia não se limitam à garantia dos direitos já consagrados juridicamente. Suas perspectivas vislumbram 
melhores condições de vida e ampliação do cânone democrático, o que extrapola o campo institucional e político e possui interface direta com a questão da economia, da transformação das bases do sistema de produção.

Na contemporaneidade, as resistências advindas das classes subalternas manifestas, sobretudo, por meio dos movimentos sociais fazem frente ao projeto de desenvolvimento neoliberal e suas implicações na política. Seus anseios requerem bem mais que a socialização dos meios de produção. Estes vislumbram maior socialização da política e do poder, em prol de uma nova ordem societária, na qual a democracia não se restrinja às "regras do jogo"(BOBBIO, 1992) para a instituição pública de interesses dominantes, mas se torne efetivamente um sistema de governo no qual as classes subalternas tenham legitimidade e acesso à partilha do poder político e da riqueza econômica, social e cultural. Desse modo, a questão do desenvolvimento nos moldes liberais é posta em cheque, uma vez que, a partir da contra-hegemonia das classes subalternas, se pode verificar a ampliação das perspectivas da democracia. A incorporação de demandas substanciais, como a má distribuição de renda, a desigualdade social e a pobreza, enquanto demandas legítimas e necessárias ao debate político sobre desenvolvimento societário torna-se uma possibilidade. A democratização dos recursos materiais, políticos e culturais e a desmistificação ideológica acerca do desenvolvimento como de crescimento econômico são imperativos para que a sociedade possa experimentar um desenvolvimento, que à luz de perspectivas contra-hegemônicas, incorpore em suas bases variáveis de natureza social. Conforme dispõe Furtado (1980, p. 16)

[...] a ideia de desenvolvimento possui pelo menos três dimensões: a do incremento da eficácia do sistema social de produção, a da satisfação de necessidades elementares da população, e a da consecução de objetivos a que almejam grupos dominantes de uma sociedade e que competem na utilização de recursos escassos. A terceira dimensão é, certamente, a mais ambígua, pois aquilo a que aspira um grupo social pode parecer simples desperdício de recursos a outros. Daí que essa terceira dimensão somente chegue a ser percebida como tal como parte de um discurso ideológico.
Acontra-hegemonia e suas resistências impõem ao Estado sua transformação. $\mathrm{O}$ desenvolvimento social passa ser escopo de mudanças na medida em que as transformações sociais perpassem o campo ideológico e político das relações entre Estado e sociedade civil, e que, a partir dessas relações, o Estado se amplie, democratizando suas bases. "Assim, a concepção de desenvolvimento de uma sociedade não é alheia a sua estrutura social, e tampouco a formulação de uma política de desenvolvimento e sua implantação são concebíveis sem preparação ideológica" (FURTADO, 1980, p. 16).

A democratização e o acesso dos sujeitos políticos vinculados às classes subalternas aos processos de formulação, execução e controle das políticas públicas (sociais), no âmbito dos poderes locais institucionalizados, se tornam caminhos concretos para a socialização das bases da democracia nos espaços locais, principalmente porque os municípios brasileiros são autônomos na condução das políticas (sociais) e já existem preceitos constitucionais que asseguram a participação da sociedade civil em seus processos de condução no âmbito dos poderes locais institucionalizados. Assim, o "[...] campo de ação das lutas democratizantes se estende para abranger não só o sistema político, mas também o futuro do "desenvolvimento" e a erradicação de desigualdades sociais [...]" (ALVAREZ, DAGNINO E ESCOBAR, 2000, p. 16).

A partir do processo de descentralização ${ }^{9}$ político-administrativa no país, os poderes locais institucionalizados passaram a ser protagonistas no acesso da sociedade civil ao Estado, por meio da implantação dos espaços institucionalizados participativos, quais sejam os conselhos gestores de políticas públicas. Porém, somente a instituição legal de tais espaços de participação não garante o fortalecimento da democracia nos poderes locais, conquanto abre um leque de possibilidades para ao processo de democratização.

O poder local institucionalizado, enquanto um complexo conjunto de relações que permite o encontro entre a hegemonia e a contra-hegemonia permite que um campo aberto de interesses, anseios

\footnotetext{
9 “'Descentralização aqui significa genericamente a "institucionalização no plano local de condições técnicas para a implementação de tarefas de gestão de políticas sociais"' (ARRETCHE, 2000, p. 16).
} 
e valores, seja (re)construído no espaço-territorial, ${ }^{10}$ a partir dos espaços democráticos, representativos e participativos, presentes na esfera municipal. A possibilidade de coexistência ou de cisão entre hegemonia e contra-hegemonia, pode favorecer possíveis práticas democráticas capazes de rearticular a relação entre Estado e sociedade civil, reconfigurando a hegemonia no espaço local. No poder local institucionalizado, a participação da sociedade civil se materializa por meio dos conselhos gestores de políticas públicas. Esses espaços institucionalizados de participação são capazes de contribuir para o fortalecimento da democracia, mediante a incorporação de perspectivas ideopolíticas, socioculturais de desenvolvimento, próprias dos sujeitos políticos da sociedade civil. Assim, o poder local institucionalizado "[...] passou a ser visto como espaço de gestão político-administrativo e não como simples sede das elites (econômicas, sociais e políticas). Mudanças na conjuntura política e no cenário econômico explicam tais alterações" (GOHN, 2005b, p. 27).

Assim, pensar o desenvolvimento social nos municípios brasileiros, a partir da lógica de desenvolvimento das políticas públicas (sociais), implica necessariamente refletir sobre as lutas contra-hegemônicas, em meio ao desenvolvimento da sociedade capitalista contemporânea; sobre a participação da sociedade civil e dos sujeitos vinculados às classes subalternas em uma perspectiva contra-hegemônica à ordem do capital e suas resistências frente à lógica de desenvolvimento neoliberal, suas influências na estruturação e socialização do poder no contexto das instituições democráticas, bem como frente ao desenvolvimento das políticas públicas (sociais), como bases para a reconstrução da hegemonia nas esferas locais em relação aos processos de desenvolvimento social municipal. Coutinho (2006, p. 22) alerta que "[...] o processo de ampliação da democracia implica choques permanentes com a lógica privatista do capital".

\section{Conclusão}

No âmbito do projeto democrático na contemporaneidade, as relações entre Estado e sociedade ci-

\footnotetext{
${ }^{10}$ Segundo Haesbaert (2006, p. 121) “[...] território é o produto de uma relação desigual de forças, envolvendo o domínio ou controle político econômico do espaço e sua apropriação simbólica, ora conjugados e mutuamente reforçados, ora desconectados e contraditoriamente articulados".
}

vil guardam intensos conflitos de valores, de interesses e de posição entre si, uma vez que o substrato das relações democráticas está constituído por diferentes perspectivas ideopolíticas, socioculturais e de desenvolvimento que se expressam no contexto do Estado. Por meio das lutas travadas pela disputa do poder e da riqueza socialmente construída no no espaço da arena democrática, se busca o estabelecimento da hegemonia na sociedade capitalista.

$\mathrm{Na}$ modernidade, as classes dominantes estruturaram uma democracia aos moldes liberais. Entretanto, as perspectivas democráticas contra-hegemônicas sempre estiveram presentes na sociedade e surgiram no debate político enquanto alternativas propostas pelos sujeitos políticos vinculados às classes subalternas, tencionando o Estado liberal para a sua democratização e abertura para a sociedade civil. A busca da socialização da política, do poder e dos meios de produção, da riqueza econômica, social e cultural tornou-se historicamente o desejo dos grupos contra-hegemônicos frente aos intentos das classes dominantes, questões essas que formam as perspectivas democráticas, contra-hegemônicas à democracia liberal.

No Brasil, o projeto democrático adquire uma face plural, porém é herdeiro de um ranço cultural eurocêntrico, que historicamente compôs uma política paternalista e clientelista, tuteladora das classes subalternas, como forma de mantê-las dominadas e domesticadas mediante a universalização de valores capitalistas burgueses. O processo de democratização no país obteve grandes avanços no período da década de 1980, sobretudo com a promulgação da Constituição Federal em 1988, por meio da qual se conquistou, dentre outros avanços, a garantia da estruturação dos institutos democráticos participativos; a federalização; a descentralização político-administrativa e a municipalização das políticas públicas (sociais). Com efeito, os municípios brasileiros passaram a ser um campo fértil de análise dos limites e das possibilidades da democracia no país, bem como uma das esferas centrais para se pensar o desenvolvimento social, uma vez que o poder local institucionalizado se constituiu em um dos protagonistas na gestão das políticas públicas (sociais), a partir de 1988.

Com a federalização e o processo de descentralização e municipalização das políticas 
públicas, mediante a autonomia políticoadministrativa adquirida pelas municipalidades, os poderes locais institucionalizados tornaram-se capazes não só de experimentar processos políticos já instituídos e vinculados às demais esferas federativas, como também de criar e (re)criar espaços e experiências políticas, por meio da sua relação com os diferentes sujeitos políticos presentes na sociedade civil local.

Assim, as perspectivas ideopolíticas, socioculturais e de desenvolvimento oriundas da sociedade civil nos poderes locais tornam-se fundamentais para a formação e para o desenvolvimento das municipalidades no Brasil. Uma vez incorporadas pela estrutura estatal, tais perspectivas possibilitam aos diferentes sujeitos políticos um aprendizado político democrático. A incorporação de seus princípios, valores, interesses e demandas possibilitam uma maior socialização da política e da partilha do poder entre as diferentes classes sociais existentes no espaço local, abrindo espaço para a contribuição da contra-hegemonia nos municípios brasileiros, na medida em que resiste às determinações hegemônicas, advindas dos interesses das classes dominantes.

Explorar com profundidade as perspectivas ideopolíticas, culturais e de desenvolvimento presentes na sociedade civil, identificando, caracterizando e compreendendo os elementos de sustentação da sua prática participativa no âmbito dos conselhos municipais gestores de políticas públicas, se torna um imperativo ao desenvolvimento democrático na contemporaneidade. Traçar indicativos da contribuição da sociedade civil para o desenvolvimento da democracia nos poderes locais, enfocando, nesse processo, as possibilidades de conquistas de direitos e de avanços nas políticas públicas sociais locais frente ao processo de desenvolvimento social municipal, torna-se, também, um desafio para os avanços democráticos no Brasil, com relação à importância da incorporação na política de novos elementos inscritos na esfera da sociedade civil, principalmente daqueles derivados de um pensamento orgânico vinculado aos sujeitos políticos e intelectuais vinculados com as classes subalternas. Vislumbrar a possibilidade de conquistar novos patamares de desenvolvimento social municipais, pelos quais a dimensão da coletividade se sobreponha à universalização dos interesses dominantes, é a força motriz para pensar o desenvol- vimento social enquanto possibilidade de liberdade, por meio da democratização da política no domínio dos poderes locais institucionalizados.

Os diferentes segmentos da sociedade civil podem contribuir, portanto, com seus diversos princípios, valores e práticas que, uma vez absorvidos e materializados nos espaços institucionalizados de participação no poder local podem cooperar para o desenvolvimento das instituições democráticas nas esferas municipais, bem como auxiliar o desenvolvimento social municipal, tornando-se elementos relevantes a serem investigados.

Os conselhos gestores de políticas públicas são espaços oportunos de luta e de conquista de direitos por parte da sociedade civil junto ao Estado. Não sendo, portanto, exclusivos, uma vez que as relações entre Estado e sociedade civil possuem outros espaços de luta que mediam demandas inerentes aos conflitos de classe, mas, uma vez garantidos e materializados dentro dos poderes institucionalizados, transformam-se em importantes espaços que, em articulação com outros segmentos sociais de vocação emancipatória e ou transformadora, constituem-se férteis para a investigação das contribuições da sociedade civil para o processo de gestão das políticas públicas (sociais) no âmbito dos poderes locais. Tais espaços abrem caminhos para a reconstrução da hegemonia nos poderes locais, nos quais a gestão participativa das políticas públicas (sociais) pode incorporar perspectivas contra-hegemônicas presentes na sociedade civil local, impactando diretamente nos rumos do desenvolvimento social nos municípios brasileiros, bem como nas instituições democráticas no país.

Há que se investir, portanto, na prática social democrática e na materialização dos preceitos institucionalizados dentro dos municípios brasileiros, de forma que Estado e sociedade civil se articulem, por meio dos conselhos gestores de políticas públicas, frente à incorporação das diferentes perspectivas ideopolíticas, socioculturais e de desenvolvimento coexistentes entres os diferentes sujeitos políticos presentes na sociedade civil nos poderes locais.

\section{Referências}

ALVAREZ, S. E., DAGNINO, E., ESCOBAR, A. O cultural e o político nos movimentos sociais latino-americanos. In: Cultura Política nos movimentos sociais latino-americanos: novas leituras. Belo Horizonte: Ed. UFMG, 2000. 
ARRETCHE, M. T. da S. Estado Federativo e Políticas Sociais: determinantes da descentralização. Rio de Janeiro: Revan, São Paulo: FAPESP: 2000, 304 p.

BIDARRA, Z. S. Conselhos gestores de políticas públicas: uma reflexão sobre os desafios para a construção dos espaços públicos. Revista Serviço Social \& Sociedade. São Paulo: Cortez, $n^{\circ} 78$, ano XXIV, jul. 2004, p. 5-47.

BOBBIO, N. O Futuro da democracia: uma defesa das

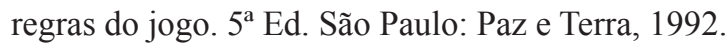

COUTINHO, C. N. Democracia e Socialismo: questões de princípio. In: Contra a corrente: ensaios sobre democracia e socialismo. São Paulo: Cortez, 2000, p. 17-48.

Democracia: um conceito em disputa. In: Intervenções: o marxismo na batalha das ideias.

São Paulo: Cortez, 2006, p. 13-28.

. O conceito de sociedade civil em Gramsci e a luta ideológica no Brasil de hoje. In: Intervenções: 0 marxismo na batalha das ideias. São Paulo: Cortez, 2006.

DURIGUETTO, M. L. Sociedade Civil e Democracia: um debate necessário. São Paulo: Cortez, 2007.

DURiguetTO, M. L., SOUZA, A. R., SilvA, K. N. Sociedade civil e movimentos sociais: debate teórico e ação prático-política. Revista Katálysis. Florianópolis, v. 12, n 1, p. 11-12, jan./jun. 2009.

FISCHER, T. Poder Local: Um tema em Análise. In: Poder Local: governo e cidadania. Rio de Janeiro: FGV, 1993, p. 10-20.

FURTADO, C. Pequena introdução ao desenvolvimento: enfoque interdisciplinar: São Paulo: Nacional, 1980.

GOHN, M. da G. O protagonismo da sociedade civil: Movimentos sociais, ONGs e redes solidárias. São Paulo: Cortez, 2005a.

GOHN, M. da G. Comunidade: origens, ressignificações e articulações com o poder local. In: SOUZA, M. A. de; COSTA, L. C. da. Sociedade e Cidadania: desafios para o século XXI. Ponta Grossa: UEPG: 2005b, parte 1, p. 14-71.

GRAMSCI, Antonio. Cadernos do cárcere. $2^{\mathrm{a}}$ ed. Rio de Janeiro: Civilização Brasileira, vol. 1, 2001.

GRUPPI, L. Conceito de hegemonia em Gramsci. Rio de Janeiro: Graal, 1978.

HAESBAERT, R. Territórios Alternativos. 2 ed. São Paulo, Contexto, 2006, $173 \mathrm{p}$.

MOTA, A. E. Cultura da crise e Seguridade Social: um estudo sobre as tendências da Previdência e da Assistência Social brasileira nos anos 1980 e 1990. São Paulo: Cortez, 2005.

PERISSINOTTO, R. M. Poder e participação no Conselho Municipal de Assistência Social de Curitiba. In: FUKS, M.,
PERRISSINOTTO, R. M., SOUZA, N. R. de. Democracia e Participação: os conselhos gestores do Paraná. Curitiba: Editora UFPR, 2004.

SÁNCHEZ VÁZQUEZ, A. Entre a realidade e a utopia: ensaios sobre política, moral e socialismo. Rio de Janeiro: Civilização Brasileira, 2001.

SCHLESENER, A. H. Hegemonia e cultura: Gramsci. 3. ed. Curitiba: Editora UFPR, 2007.

SEMERARO, Giovanni. Gramsci e a sociedade civil: cultura e educação para a democracia. Petrópolis: RJ: Vozes, 2. ed. 1999.

SILVA E SILVA, M. O. Editorial. Revista Katálysis. Florianópolis, v. 12, n 1, p. 11-12, jan./jun. 2009.

SIMIONATTO, I. Gramsci: sua teoria, incidência no Brasil, influência no serviço social. Florianópolis: Ed. da UFSC; São Paulo: Cortez, 1999.

SIMIONATTO, I. Classes subalternas, lutas de classe e hegemonias: uma abordagem gramsciana. Revista Katálysis. Florianópolis, v. 12, n 1, p. 11-12, jan./jun. 2009.

TATAGIBA, L. Os Conselhos Gestores e a Democratização das Políticas Públicas no Brasil. In: DAGNINO, E. (org). Sociedade Civil e Espaços Públicos no Brasil. São Paulo: Paz e Terra, 2002, p. 47-103.

TEIXEIRA, E. C. O local e o global: limites e desafios da participação cidadã. São Paulo: Cortez; Recife: EQUIP; Salvador: UFBA, 2001.

VIEIRA, Evaldo. Os Direitos e a Política Social. São Paulo: Cortez, 1992.

Recebido em 28 de junho de 2013

Aceito em 08 de outubro de 2013 